tior 1 gurects of standarda

Iibrary, N.W. BIdg -

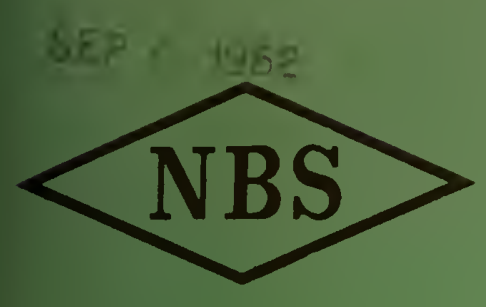

Eechnical Note

\title{
MODE CONVERSION IN THE EARTH-IONOSPHERE WAVEGUIDE
}

\author{
JAMES R. WAIT
}

U. S. DEPARTMENT OF COMMERCE

NATIONAL BUREAU OF STANDARDS 


\section{THE NATIONAL BUREAU OF STANDARDS}

\section{Functions and Activities}

The functions of the National Bureau of Standards are set forth in the Act of Congress, March 3, 1901, as amended by Congress in Public Law 619, 1950. These include the development and maintenance of the national standards of measurement and the provision of means and methods for making measurements consistent with these standards; the determination of physical constants and properties of materials; the development of methods and instruments for testing materials; devices, and structures; advisory services to government agencies on scientific and technical problems; invention and development of devices to serve special needs of the Government; and the development of standard practices, codes, and specifications. The work includes basic and applied research, development, engineering, instrumentation, testing, evaluation, calibration services, and various consultation and information services. Research projects are also performed for other government agencies when the work relates to and supplements the basic program of the Bureau or when the Bureau's unique competence is required. The scope of activities is suggested by the listing of divisions and sections on the inside of the back cover.

\section{Publications}

The results of the Bureau's research are published either in the Bureau's own series of publications or in the journals of professional and scientific societies. The Bureau itself publishes three periodicals available from the Government Printing Office: The Journal of Research, published in four separate sections, presents complete scientific and technical papers; the Technical News Bulletin presents summary and preliminary reports on work in progress; and Basic Radio Propagation Predictions provides data for determining the best frequencies to use for radio communications throughout the world. There are also five series of nonperiodical publications: Monographs, Applied Mathematics Series, Handbooks, Miscellaneous Publications, and Technical Notes.

A complete listing of the Bureau's publications can be found in National Bureau of Standards Circular 460, Publications of the National Bureau of Standards, 1901 to June 1947 (\$1.25), and the Supplement to National Bureau of Standards Circular 460, July 1947 to June 1957 (\$1.50), and Miscellaneous Publication 240, July 1957 to June 1960 (Includes Titles of Papers Published in Outside Journals 1950 to 1959)(\$2.25); available from the Superintendent of Documents, Government Printing Office, Washington 25, D. C. 


\title{
NATIONAL BUREAU OF STANDARDS Eechnical Note
}

JUNE 8, 1962

\author{
MODE CONVERSION IN THE \\ EARTH-IONOSPHERE WAVEGUIDE
}

James R. Wait

NBS Boulder Laboratories

NBS Technical Notes are designed to supplement the Bureau's regular publications program. They provide a means for making available scientific data that are of transient or limited interest. Technical Notes may be listed or referred to in the open literature. 


\section{CONTENTS}

$$
\text { Page }
$$

1. Introduction-..... 2

2. Formulation-

3. Discussion of Formulae-

4. References-_. 17

Figures-1. 18 
by

James R. Wait

Central Radio Propagation Laboratories

National Bureau of Standards

Boulder, Colo.

\section{Abstract}

An approximate theory for conversion of modes in an earthionosphere waveguide is propounded. The model is two concentric spherical reflecting boundaries which have prescribed surface impedances. The localized irregularity at either the ground or the ionosphere is idealized by a "black screen" which effectively blocks the cross-section of the waveguide over a portion of its area. In this sense, the method is a union of approximate Kirchoff diffraction theory and rigorous mode theory.

The research reported in this document has been supported, in part,by the Advanced Research Projects Agency. 


\section{Introduction}

In the theory of VLF propagation it is usually assumed that the ionosphere is concentric with the surface of a spherical earth. In many actual cases, this is often an excellent approximation. In fact, even if the ionospheric height changes slowly in a horizontal direction the modes do not change their individual character. However, if the changes are abrupt, and occur in a very localized region, conversion of energy from one mode to another may result [Wait, 1962a].

In this paper the general problem is studied from a fresh viewpoint. A localized irregularity is imagined to be equivalent to blocking the aperture which is the cross-section of the waveguide. The method is applicable to irregularities at both the ionospheric reflecting layer as well as at the earth's surface. An example in the last category would be a mountain ridge which is transverse to the propagation path.

The method is based on a union of approximate Kirchoff diffraction theory and rigorous mode theory. To simplify the discussion, the problem is considered to be two-dimensional in nature and, thus, the equivalent source is a line dipole.

\section{Formulation}

We initiate the analysis with a simple model. The earth's surface and a reflecting layer are represented by two concentric cylindrical surfaces with curvature radii of $a$ and $a+h$, respectively. In terms of cylindrical coordinates $(r, \theta, z)$ concentric surfaces are $r=a$ and $\mathrm{a}+\mathrm{h}$. The situation is illustrated in Fig. 1. The surface impedances at the lower and upper surface are denoted by $z_{g}$ and $z_{i}$, respectively. The fields are assumed to vary according to $\exp (i \omega t)$. 
The fields in such a region can be expressed as a superposition of transverse electric ( $T E$ ) and transverse magnetic (TM) modes. We will just consider the TM modes since they are of greatest practical interest at VLF. The analysis for the TE modes is almost identical.

For the TM modes the magnetic field has only an axial component $\mathrm{H}$ (i.e., out of the paper in Fig. 1). The electric field has only $r$ and $\theta \quad$ components and they can be obtained simply by differentiating $\mathrm{H}$.

We now imagine that the fields at the aperture plane $\theta=\theta_{0}$ are known. For example $\mathrm{H}\left(\theta_{0}, r\right)$ is specified over the interval $\mathrm{a}<\mathrm{r}<\mathrm{a}+\mathrm{h}$. Thus, for the region $\theta>\theta_{0}$ the field will consist of TM modes travelling in the positive $\theta$ direction. Furthermore, these modes must satisfy the boundary conditions

$$
\begin{aligned}
& E_{\theta}=-Z_{g} H \text { at } \quad r=a \\
& E_{\theta}=Z_{i} H \text { at } r=a+h .
\end{aligned}
$$

Under the assumptions

$$
\begin{aligned}
& \mathrm{k} a>>1, \\
& \mathrm{~h} / \mathrm{a}<<1, \\
& \theta<<1,
\end{aligned}
$$

it was shown previously that [Wait, 1961] the field could be represented 
in the form

$$
H=H(x, y)=\sum_{n=1,2,3} A_{n} \Phi\left(t_{n}, y\right) e^{-i\left(x-x_{0}\right) t_{n}}
$$

where

$x=\left(\frac{k a}{2}\right)^{\frac{1}{3}} \theta, \quad x_{0}=\left(\frac{k a}{2}\right)^{\frac{1}{3}} \theta_{0}, y=\left(\frac{2}{k a}\right)^{\frac{1}{3}} k(x-a), \quad$ and $y_{0}=\left(\frac{2^{\frac{1}{3}}}{k a} k h\right.$.

The function $\Phi$ satisfies the differential equation

$$
\left(\frac{d^{2}}{d y^{2}}-t+y\right) \Phi(t, y)=0
$$

and $t_{n}$ are obtained from

$$
\left.\frac{d}{d y} \Phi\left(t_{n}, y\right)\right]+q\left(_{n}, 0\right)=0
$$

where

$$
\text { i } q=\left(\frac{\mathrm{ka}}{2}\right)^{\frac{1}{3}} \frac{\mathrm{Z}}{\mathrm{g}}
$$

and

$$
\left.\frac{d}{d y} \Phi\left(t_{n}, y\right)\right]-q_{i} \Phi\left(t_{n}, y_{o}\right)=0
$$

where

$$
i q_{i}=\left(\frac{k a}{2}\right)^{\frac{1}{3}} \frac{z_{i}}{120 \pi} \text {. }
$$


The latter two equations are equivalent to the boundary conditions given by (1) and (2).

Solutions of (4) are linear combinations of the Airy integral functions $w_{1}(t-y)$ and $w_{2}(t-y)$. In terms of the functions $A i(\alpha)$ and $B i(\alpha)$, defined and tabulated by Miller [1946],

$$
\mathrm{w}_{1}(\alpha)=\sqrt{\pi}[\mathrm{Bi}(\alpha)-\mathrm{i} \mathrm{Ai}(\alpha)]
$$

and

$$
\mathrm{w}_{2}(\alpha)=\sqrt{\pi}[\mathrm{Bi}(\alpha)+\mathrm{i} \mathrm{Ai}(\alpha)]
$$

It is easy to verify that

$$
\Phi\left(t_{n}, y\right)=w_{1}\left(t_{n}-y\right)+A\left(t_{n}\right) w_{2}\left(t_{n}-y\right)
$$

where

$$
A(t)=-\left[\frac{w_{1}\left(t-y_{0}\right)+q_{i} w_{1}\left(t-y_{0}\right)}{w_{2}^{\prime}\left(t-y_{0}\right)+q_{i} w_{2}\left(t-y_{0}\right)}\right],
$$

satisfies (6). Furthermore, if

$$
A\left(t_{n}\right) B\left(t_{n}\right)=1=e^{-i 2 \pi n}
$$

where

$$
B(t)=-\left[\frac{w_{2}^{\prime}(t)-q w_{2}(t)}{w_{1}^{\prime}(t)-q w_{1}(t)}\right]
$$

it is seen that $\Phi$ also satisfies (5). 
It should be mentioned at this stage that the surface $r=a+h$ can be regarded as a reference surface where the ratio of the tangential fields are specified. In the general case $z_{i}$ or $q_{i}$ may be a function of the eigen-values $t_{n}$. However, for VLF it is a good approximation to regard $z_{i}$ or $q_{i}$ as constants. This is equivalent to stating that the surface impedance does not depend on the angle of incidence. In a similar manner $Z_{g}$ or $q$ can be regarded as constants.

The orthogonality properties of the modes are now studied. We consider two sets of values, $t_{n}$ and $t_{m}$, which satisfy the boundary equations (5) and (6). However, for any value of $y$ these must also satisfy

$$
\frac{\mathrm{d}^{2}}{\mathrm{dy} \mathrm{y}^{2}} \Phi_{\mathrm{n}}-\left(\mathrm{t}_{\mathrm{n}}-\mathrm{y}\right) \Phi_{\mathrm{n}}=0 \quad, \quad \Phi_{\mathrm{n}}=\Phi\left(\mathrm{t}_{\mathrm{n}}, \mathrm{y}\right)
$$

and

$$
\frac{\mathrm{d}^{2}}{\mathrm{dy}^{2}} \Phi_{\mathrm{m}}-\left(\mathrm{t}_{\mathrm{m}}-\mathrm{y}\right) \Phi_{\mathrm{m}}=0, \Phi_{\mathrm{m}}=\Phi\left(\mathrm{t}_{\mathrm{m}}, \mathrm{y}\right)
$$

After multiplying the first of these equations by $\Phi_{\mathrm{m}}$ and the second by $\Phi_{n}$ they are subtracted from one another. Both sides of the resulting equations are then integrated with respect to $y$ over the range 0 to $y_{0} \cdot$ This results in

$$
\left.\Phi_{\mathrm{n}} \frac{\mathrm{d}}{\mathrm{dy}} \Phi_{\mathrm{m}}-\Phi_{\mathrm{m}} \frac{\mathrm{d}}{\mathrm{dy}} \Phi_{\mathrm{n}}\right]_{0}^{\mathrm{y}_{\mathrm{o}}}=\left(\mathrm{t}_{\mathrm{n}}-\mathrm{t}_{\mathrm{m}}\right) \int_{0}^{\mathrm{y}_{\mathrm{o}}} \Phi_{\mathrm{n}} \Phi_{\mathrm{m}} \mathrm{dy} .
$$


In view of the boundary conditions on $\Phi_{n}$ and $\Phi_{m}$ at $y=0$ and $y=y_{0}$, the left-hand side of the preceding equation is zero. Thus, the integral on the right also vanishes if $t_{n}$ is not equal to $t_{m}$.

Therefore, we have the important result

$$
\int_{0}^{y_{0}} \Phi\left(t_{m}, y\right) \Phi\left(t_{n}, y\right) d y=0 \text { if } m \neq n \text {. }
$$

It now follows that, if both sides of (3) are multiplied by $\Phi\left(t_{m}, y_{0}\right)$ and integrated from 0 to $y_{0}$,

$$
A_{n}=\frac{\int_{0}^{y_{0}} H\left(x_{0}, y\right) \Phi\left(t_{n}, y\right) d y}{\int_{0}^{y_{0}}\left[\Phi\left(t_{n}, y\right)\right]^{2} d y} .
$$

The normalizing integral

$$
N_{n}=\int_{0}^{y}\left[\Phi\left(t_{n}, y\right)\right]^{2} d y
$$

is now expressed in a more convenient form. This is accomplished by noting that

$\int\left[\Phi\left(t_{n}, y\right)\right]^{2} d y=-\left(t_{n}-y\right)\left[\Phi\left(t_{n}, y\right)\right]^{2}+\left[\Phi^{\prime}\left(t_{n}, y\right)\right]^{2}$. 
This can be proved by differentiating both sides with respect to $y$ and making use of (13). Then using the definition of $\Phi\left(t_{n}, y\right)$ in terms of Airy functions, it follows that

$$
\Phi\left(t_{n}, 0\right)=-\frac{2 i}{w_{2}^{\prime}\left(t_{n}\right)-q w_{2}\left(t_{n}\right)}
$$

and

$$
\Phi\left(t_{n}, y_{0}\right)=-\frac{2 i}{w_{2}^{\prime}\left(t_{n}-y_{0}\right)+q_{i} w_{2}\left(t_{n}-y_{o}\right)}
$$

whe re use is also made of the Wronskian condition

$$
w_{1}(t) w_{2}^{1}(t)-w_{1}^{1}(t) w_{2}(t)=-2 i
$$

which is valid for any value of t. Finally, on making use of (19), (20), and (21) along with (5) and (6), it is found that

$$
\begin{aligned}
& N_{n}=-\frac{4\left(t_{n}-q^{2}\right)}{\left[w_{2}^{\prime}\left(t_{n}\right)-q w_{2}\left(t_{n}\right)\right]^{2}} \\
& \quad+\frac{4\left(t_{n}-y_{0}-q_{i}^{2}\right)}{\left[w_{2}^{\prime}\left(t_{n}-y_{0}\right)+q_{i} w_{2}\left(t_{n}-y_{0}\right)\right]^{2}} .
\end{aligned}
$$

This can be regarded as a fairly important result.

Equation (17) for the coefficient $A_{n}$ can be written in the convenient form

$$
A_{n}=\frac{2 \Lambda_{n}}{y_{0}} \frac{\int_{0}^{y_{0}} H\left(x_{0}, y\right) \Phi\left(t_{n}, y\right) d y}{\left[\Phi\left(t_{n}, 0\right)\right]^{2}}
$$


where

$$
\Lambda_{n}=\frac{y_{0}}{2}\left[\left(t_{n}-q^{2}\right)-\left(t_{n}-y_{0}-q_{i}^{2}\right)\left(\frac{w_{2}^{1}\left(t_{n}\right)-q_{2}\left(t_{n}\right)}{w_{2}^{1}\left(t_{n}-y_{0}\right)+q_{i} w_{2}\left(t_{n}-y_{0}\right)}\right)^{2}\right] .
$$

It is now imagined that the incident field results from an equivalent line magnetic source at $\mathrm{x}=0$ (i.e., $\theta=0$ ). Thus,

$$
H(x, y)=\sum_{m} \underset{m}{a} \Phi\left(t_{m}, y\right) e^{-i x t_{m}} \text { for } x<x_{o}
$$

where $a_{m}$ is a coefficient which does not depend on $x$ or $y$. It is assumed that in the aperture plane $x_{0} x_{0}$ is obstructed in such a manner that the effective aperture is a slit extending from $y=y_{1}$ to $y_{2}$ (i.e., $r-a=z_{1}$ to $z_{2}$ ). The situation is illustrated in Fig. 2 . Thus, within the Kirchoff approximation,

$$
\begin{aligned}
H\left(x_{0}, y\right) & \left.=\sum_{m} a_{r n}, y\right) e^{-i x_{0} t_{m}} \quad \text { for } y_{1}>y>y_{2} \\
& =0 \quad \text { for } 0<y<y_{1} \\
& =0 \quad \text { for } y_{2}<y<y_{o} .
\end{aligned}
$$

In other words, we are assuming that the field within the aperture of the slit has the same value as if the slit were not present. It is known from a study of the rigorous solutions of diffraction by slits that this is an excellent approximation [Born and Wolf, 1959] provided the width of the slit is greater than about a wavelength. 
The field in the region $x>x_{0}$ can now be expressed in the form

$$
H(x, y)=\sum_{m} \sum_{n} A_{n}^{(m)} \Phi\left(t_{n}, y\right) e^{-i\left(x-x_{0}\right) t_{n}} e^{-i x_{0} t_{m}}
$$

where

$$
A_{n}^{(m)}=\frac{2 \Lambda_{n}}{y_{0}} \frac{\int_{y_{1}}^{y_{2}} \Phi\left(t_{m}, y\right) \Phi\left(t_{n}, y\right) d y}{\left[\Phi\left(t_{n}, 0\right)\right]^{2}} a_{m} .
$$

We see clearly that the incident mode of order $m$ excites modes of order $n$ where $m$ and $n$ are positive integers.

It is convenient to write

$$
A_{n}^{(m)}=\left[P_{n}^{(m)}+Q_{n}^{(m)}\right] a_{m}
$$

where, for $m \neq n$,

$$
P_{n}(m)=-\frac{2 \Lambda_{n}}{y_{0}} \frac{\Phi\left(t_{m}, 0\right)}{\Phi\left(t_{n}, 0\right)} \int_{0}^{y_{1}} G_{m}(y) G_{n}(y) d y,
$$

and

$$
Q_{n}^{(m)}=-\frac{2 \Lambda_{n}}{y_{0}} \frac{\Phi\left(t_{m}, 0\right)}{\Phi\left(t_{n}, 0\right)} \int_{y_{2}}^{y_{0}} G_{m}(y) G_{n}(y) d y,
$$

where

$$
G_{n}(y)=\frac{\Phi\left(t_{n}, y\right)}{\Phi\left(t_{n}, 0\right)}
$$


and

$$
G_{m}(y)=\frac{\Phi\left(t_{m}, y\right)}{\Phi\left(t_{m}, 0\right)}
$$

In obtaining the above forms for $\mathrm{P}_{\mathrm{n}}^{(\mathrm{m})}$ and $\mathrm{Q}_{\mathrm{n}}^{(\mathrm{m})}$ use has been made of the orthogonality condition given by (16).

When $\mathrm{m}=\mathrm{n}$, we have

$$
A_{n}^{(n)}=\left[P_{n}^{(n)}+Q_{n}^{(n)}\right] a_{n}
$$

where

$$
P_{n}^{(n)}=1-\frac{2 \Lambda_{n}}{y_{0}} \int_{0}^{y_{1}}\left[G_{n}(y)\right]^{2} d y
$$

and

$$
Q_{n}^{(n)}=1-\frac{2 \Lambda_{n}}{y_{0}} \int_{y_{2}}^{y_{0}}\left[G_{n}(y)\right]^{2} d y
$$

where use has been made of (23).

The integrals over the range 0 to $y_{1}$ in the preceding equations can be regarded as the influence of the obstacle on the ground, whereas the integrals over $y_{2}$ to $y_{0}$ are related to the protuberance at the ionosphere. To evaluate these integrals it is desirable to expand the $G$ functions as a power series in $y$.

Since

$$
G_{n}(0)=1
$$




$$
\left[\mathrm{d} G_{n}(y) / d y\right]_{y=0}=-q
$$

and

$$
\frac{d^{2} G(y)}{d y^{2}}=\left(t_{n}-y\right) G(y) \text { for any } y
$$

it is not difficult to show that

$$
G_{n}(y)=1-q y+\frac{t_{n} y^{2}}{2}-\frac{\left(1+t_{n} q\right)}{6} y^{3}+\ldots .
$$

Thus,

$$
\begin{aligned}
G_{n}(y) G_{m}(y)=1-2 q y & +\left(t_{n}+t_{m}+2 q^{2}\right) \frac{y^{2}}{2} \\
& -\left(1+2 t_{n} q+2 t_{m} q\right) \frac{y^{3}}{3}+\ldots
\end{aligned}
$$

and the expansion for $\left[G_{n}(y)\right]^{2}$ is obtained by simply replacing $t_{m}$ by $t_{n}$ in the preceding result.

The integrations for the $P$ integrals are now readily carried out. They yield

$$
\begin{aligned}
& \mathrm{P}_{\mathrm{n}}^{(\mathrm{m})}=-\frac{2 \Lambda_{\mathrm{n}}}{\mathrm{y}_{\mathrm{o}}} \mathrm{g}_{\mathrm{m}, \mathrm{n}}\left[\mathrm{y}_{1}-\mathrm{q} \mathrm{y}_{1}^{2}+\left(\mathrm{t}_{\mathrm{n}}+\mathrm{t}_{\mathrm{m}}+2 \mathrm{q}^{2}\right) \frac{\mathrm{y}_{1}^{3}}{6}\right. \\
& -\left(1+2 t_{n} q+2 t_{m} \text { q) } \frac{y_{1}^{4}}{12}+\ldots\right]
\end{aligned}
$$

where

$$
g_{m, n}=\frac{\Phi\left(t_{m}, 0\right)}{\Phi\left(t_{n}, 0\right)}=\frac{w_{2}^{\prime}\left(t_{n}\right)-q w_{2}\left(t_{n}\right)}{w_{2}^{1}\left(t_{m}\right)-q w_{2}\left(t_{m}\right)}
$$


and

$$
\begin{aligned}
\mathrm{P}_{\mathrm{n}}^{(\mathrm{n})}=1-\frac{2 \Lambda_{\mathrm{n}}}{\mathrm{y}_{\mathrm{O}}}\left[\mathrm{y}_{1}-\mathrm{q} \mathrm{y}_{1}^{2}\right. & +\left(\mathrm{t}_{\mathrm{n}}+\mathrm{q}^{2}\right) \frac{\mathrm{y}_{1}^{3}}{3} \\
& \left.-\left(1+4 \mathrm{t}_{\mathrm{n}} \mathrm{q}\right) \frac{\mathrm{y}_{1}^{4}}{12}+\ldots\right] .
\end{aligned}
$$

The $Q$ integrals are evaluated in a very similar manner. Thus

$$
\begin{aligned}
Q_{n}^{(m)}= & -\frac{2 \Lambda_{n}}{y_{0}} g_{m, n} G_{m}\left(y_{0}\right) G_{n}\left(y_{0}\right)\left[\left(y_{0}-y_{2}\right)-q_{i}\left(y_{0}-y_{2}\right)^{2}\right. \\
& \left.+\left(t_{n}+t_{m}+2 q_{i}^{2}\right) \frac{\left(y_{0}-y_{2}\right)^{3}}{6}-\left(1+2 t_{n} q_{i}+2 t_{m} q_{i}\right) \frac{\left(y_{0}-y_{2}\right)^{4}}{12}+\ldots\right]
\end{aligned}
$$

and

$$
\begin{aligned}
& Q_{n}^{(n)}=1-\frac{2 \Lambda_{n}}{y_{0}}\left[G_{n}\left(y_{0}\right)\right]^{2}\left[\left(y_{0}-y_{2}\right)-q_{i}\left(y_{0}-y_{2}\right)^{2}\right. \\
& \left.+\left(t_{n}+q_{i}^{2}\right) \frac{\left(y_{0}-y_{2}\right)^{3}}{3}-\left(1+4 t_{n} q_{i}\right) \frac{\left(y_{0}-y_{2}\right)^{4}}{12}+\ldots\right]
\end{aligned}
$$

Due to the typically large values of $q_{i}$ at VLF, the preceding series for the $Q$ functions are probably not useful. It would be better to work directly with equations (32) and (37).

\section{Discussion of Formulae}

Some of the previous results are now discussed briefly. For purposes of illustration, it is assumed that the ionosphere is a sharply bounded medium whose effective conductivity is $\varepsilon_{\mathrm{O}}{ }_{\mathrm{r}}$ where $\varepsilon_{0}=8.854 \times 10^{-12}$. Under this condition extensive numerical values 
of the coefficients $t_{n}$ satisfying equation (11) are available [Spies and Wait, 1961]. Using these values, the various quantities entering into the formulas for the modal coefficients can be evaluated in a straightforward manner.

It is seen that the modal coefficients, given by equations (43), (45), (46), and (47) all contain the factor $\Lambda_{\mathrm{n}}$. This factor is a modal excitation factor and it is a measure of the efficiency of excitation of a given mode from a line or dipole source [Wait, 1961, 1962b]. In the present context it is normalized so that it approaches unity for perfect ground conductivity $(\mathrm{q}=0)$ and a flat earth $(a=\infty)$. In general it is a complex quantity. To illustrate its behavior $\omega_{r}$ is set equal to $2 \times 10^{5}$ and $h$ is taken as $70 \mathrm{~km}$. Furthermore, the ground is assumed to be perfectly conducting. Under these conditions $\Lambda_{\mathrm{n}}$ for $\mathrm{n}=1$ has the following complex values for the frequencies indicated:

$$
\begin{aligned}
\Lambda_{1}= & 0.95 \underline{3.8^{\circ}}(10 \mathrm{kc} / \mathrm{s}), \quad 0.79 \underline{3.0^{\circ}}(15 \mathrm{kc} / \mathrm{s}), \\
& 0.59 \underline{4.6^{\circ}}(20 \mathrm{kc} / \mathrm{s}), \quad 0.371 .4^{\circ}(25 \mathrm{kc} / \mathrm{s}), \\
& 0.1910 .6^{\circ}(30 \mathrm{kc} / \mathrm{s}) .
\end{aligned}
$$

This mode corresponds to the mode of least attenuation. It is characterized by an excitation factor which decreases approximately as the inverse of the frequency. Under the same conditions $\Lambda_{n}$, for $n$ greater than 1 , is roughly unity over the same frequency range [Wait, 1962b]. 
The modal coefficient $P_{n}^{(n)}$ defined by (45), in the case of $n=1$, can be written

$$
P_{1}^{(1)} \cong 1-2 \Lambda_{1} \frac{h_{1}}{h} \text {. }
$$

Here, $h_{1} / h$ is the ratio of the heights of the obstacle on the ground to the height of the ionosphere. This quantity would never be greater than about 0.05 and thus the modification of the first mode by even an extremely high mountain range would be small. This is particularly the case at the $u_{1}$ pper end of the VLF band where the excitation factor is small.

The relative conversion of the field from an incident mode of order 1 to a mode of order 2 is obtained from the factor $P_{n}^{(m)}$ defined by (43) for $m=1$ and $n=2$. Approximately, this can be written

$$
P_{2}^{(1)} \cong-2 \Lambda_{2} g_{1,2}\left(h_{1} / h\right)
$$

The complex quantity $g_{1,2}$ is defined by equation (44) for $m=1$, $\mathrm{n}=2$, and $\mathrm{q}=0$. For the same conditions, its magnitude for the frequencies indicated are given as follows

$$
\begin{aligned}
\left|g_{1,2}\right|= & 1.72(10 \mathrm{kc} / \mathrm{s}), \quad 1.47(15 \mathrm{kc} / \mathrm{s}), \quad 1.08(20 \mathrm{kc} / \mathrm{s}), \\
& 0.70(25 \mathrm{kc} / \mathrm{s}), \quad \text { and } 0.41(30 \mathrm{kc} / \mathrm{s})
\end{aligned}
$$

Since $\left|\Lambda_{2}\right|$ is of the order of unity, it is thus apparent that the conversion to higher modes may be significant. 
The influence of the protuberance on the upper boundary is described by equations (46) and (47). The situation is similar to that of the ground obstacle except that the factors $G_{n}\left(y_{o}\right)$ appear. Actually, these are the ratio of the field just below the ionosphere reflecting layer to the field at the ground.

Of particular interest is the possibility that, as a consequence of an ionospheric irregularity, a mode of order 1 may be excited by an incident mode of order 2. The magnitude of this first-order mode relative to amplitude of the second-order mode is obtained from equation (46) with $\mathrm{m}=2$ and $\mathrm{n}=2$. Thus, approximately

$$
Q_{1}^{(2)} \cong-2 \Lambda_{1} g_{2,1} G_{2}\left(y_{0}\right) G_{1}\left(y_{0}\right)\left(\frac{h-h_{2}}{h}\right)
$$

The numerical magnitude of the excitation factor $\Lambda_{1}$ has already been discussed. As noted, it may be quite small for frequencies of the order of $25 \mathrm{kc} / \mathrm{s}$. However, in certain cases, the height-gain function $G_{1}(y)$, is somewhat greater than unity. Thus, the conversion to the lower-order mode may be quite significant. This point can also be demonstrated directly from equation (32) which, in this special case, has the form

$$
Q_{1}^{(2)}=-\frac{2 \Lambda_{1}}{y_{0}} g_{2,1} \int_{y_{2}}^{y_{0}} G_{2}(y) G_{1}(y) d y .
$$

Modes of the "whispering gallery" type [Budden and Martin, 1962], also known as "earth-detached modes" [Wait, 1962t], are associated with a low excitation efficiency (i. e., $\Lambda_{1}$ is small). However, the 
height-gain function $\mathrm{G}_{1}(\mathrm{y})$ for a "whispering gallery mode" is an increasing function of height. Thus, the product of the integral over $y_{2}$ to $y_{0}$ and the excitation factor $\Lambda_{1}$ may be of appreciable magnitude.

\section{References}

Born, Max and Emil Wolf, Principles of optics (Pergamon Press, 1959). Budden, K. G., and H. G. Martin, The ionosphere as a whispering gallery, Proc. Roy. Soc. Ser. A, 265, 554-569 (1962). Miller, J.C.P., The Airy integral, giving tables of solutions of the differential equation $y^{n}=x y$ (Cambridge University Press, 1946). Spies, K.P., and J.R. Wait, Mode calculations for VLF propagation in the earth-ionosphere waveguide, NBS Technical Note No. 114 (Jul. 17, 1961).

Wait, J.R., A new approach to the mode theory of VLF propagation, J. Research NBS 65D (Radio Prop.), No. 1, 37-46 (Jan.-Feb. 1961). Wait, J.R., An analysis of VLF mode propagation for a variable ionosphere height, J. Research NBS 66D (Radio Prop.), No. 4, (Jul. -Aug。1962a).

Wait, J.R., Electromagnetic waves in stratified media (Pergamon Press, New York and London, 1962b). 


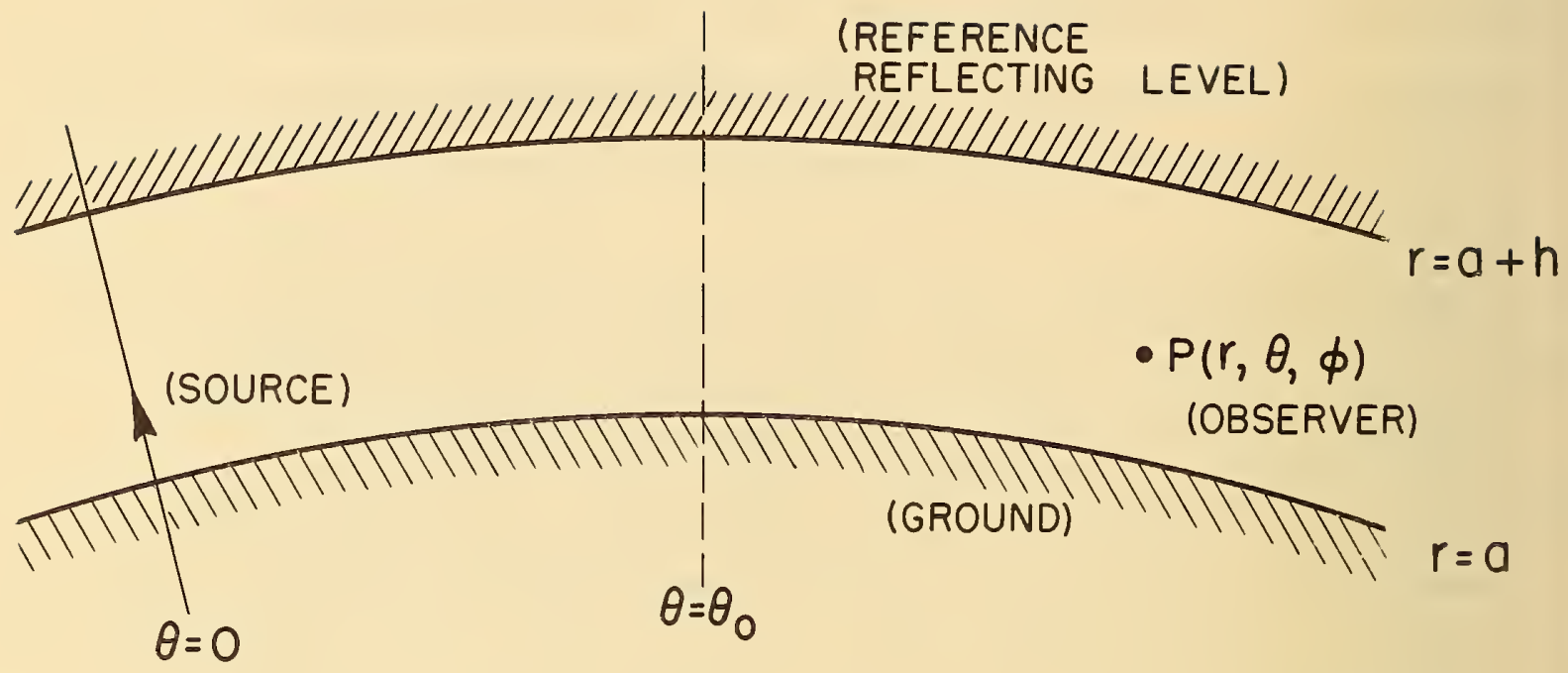

Fig. 1 - The waveguide model and the spherical coordinate system $(r, \theta, \phi)$

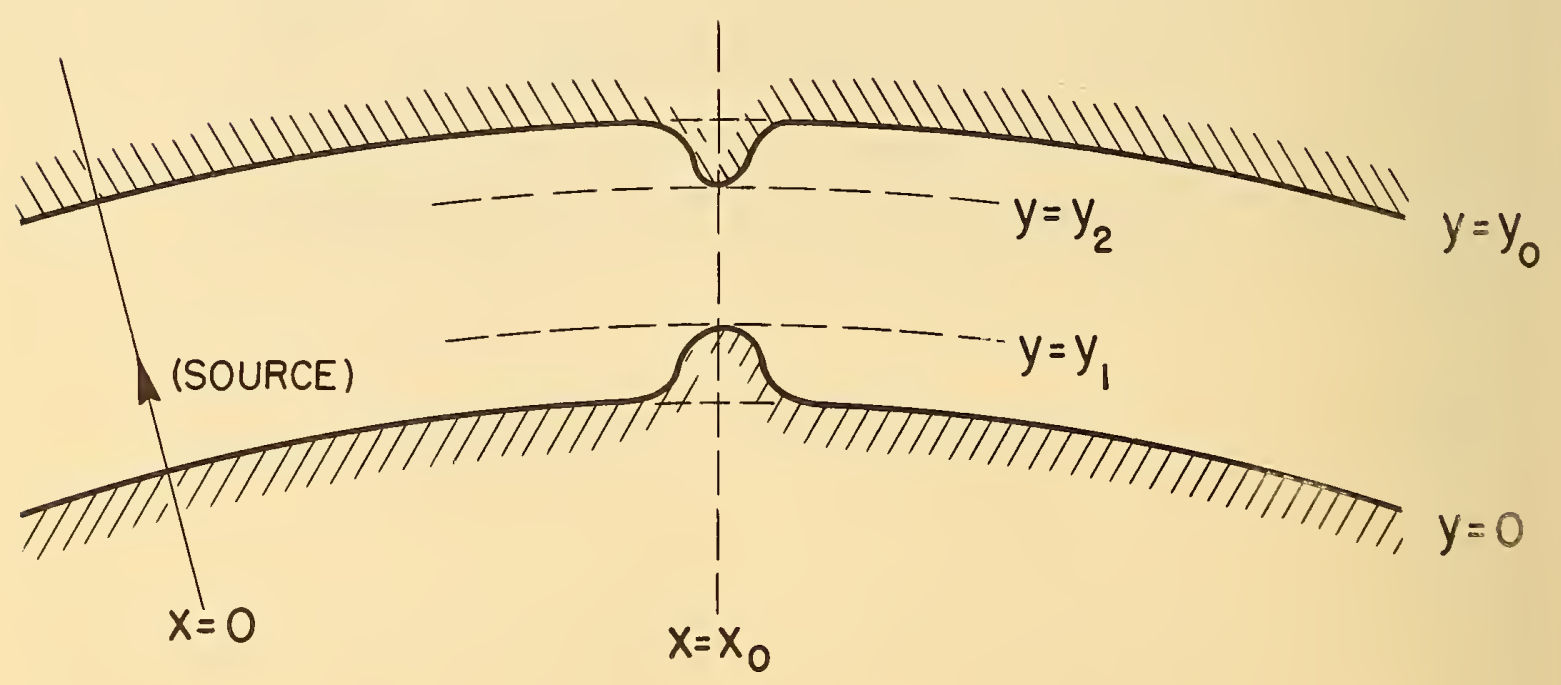

Fig. 2 - The waveguide model showing idealized obstructions in the aperture plane $\mathrm{x}=\mathrm{x}_{0^{\circ}}$. Here, the natural coordinate system $(x, y)$ is being used. 
U. S. DEPARTMENT OF COMMERCE

Luther H. Hodges, Secretary

NATIONAL BUREAU OF ST ANDARDS

A. V. Astin, Director

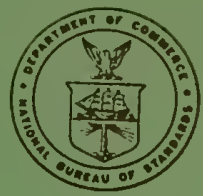

\section{THE NATIONAL BUREAU OF STANDARDS}

The scope of activities of the National Bureau of Standards at its major laboratories in Washington, D.C., and Boulder, Colorado, is suggested in the following listing of the divisions and sections engaged in technical work. In general, each section carries aut specialized research, development, and engineering in the field indicated by its title. A brief description of the activities, and of the resultant publications, appears on the inside of the front cover.

WASHINGTON, D. C.

Electricity. Resistance and Reactance. Electrochemistry. Electrical Instruments. Magnetic Measurements Dielectrics. High Voltage.

Metrology. Photometry and Colorimetry. Refractometry. Photographic Research. Length. Engineering Metrology. Mass and Scale. Volumetry and Densimetry.

Heat. Temperature Physics. Heat Measurements. Cryogenic Physics. Equation of State. Statistical Physics. Radiation Physics. X-ray. Radioactivity. Radiation Theory. High Energy Radiation. Radiological Equipment. Nucleonic Instrumentation. Neutron Physics.

Analytical and Inorganic Chemistry. Pure Substances. Spectrochemistry. Solution Chemistry. Standard Reference Materials. Applied Analytical Research. Crystal Chemistry.

Mechanics. Sound. Pressure and Vacuum. Fluid Mechanics. Engineering Mechanics. Rheology. Combustion Controls.

Polymers. Macromolecules: Synthesis and Structure. Polymer Chemistry. Polymer Physics. Polymer Characterization. Polymer Evaluation and Testing. Applied Polymer Standards and Research: Dental Research.

Metallurgy. Engineering Metallurgy. Microscopy and Diffraction. Metal Reactions. Metal Physics. Electrolysis and Metal Deposition.

Inorganic Solids. Engineering Ceramics. Glass. Solid State Chemistry. Crystal Growth. Physical Properties. Crystallogr aphy.

Building Research. Structural Engineering. Fire Research. Mechanical Systems. Organic Building Materials. Codes and Safety Standards. Heat Transfer. Inorganic Building Materials. Metallic Building Materials.

Applied Mathematics. Numerical Analysis. Computation. Statistical Engineering. Mathematical Physics. Operations Research.

Data Processing Systems. Components and Techniques. Computer Technology. Measurements Automation. Engineering Applications. Systems Analysis.

Atomic Physics. Spectroscopy. Infrared Spectroscopy. Solid State Physics. Electron Physics. Atomic Physics. Instrumentation. Engineering Electronics. Electron Devices. Electronic Instrumentation. Mechanical Instruments. Basic Instrumentation.

Physical Chemistry. Thermochemistry. Surface Chemistry. Organic Chemistry. Molecular Spectroscopy. Molecular Kinetics. Mass Spectrometry.

Office of Weights and Measures.

BOULDER, COLO.

Cryogenic Engineering Laboratory. Cryogenic Equipment. Cryogenic Processes. Properties of Materials. Cryogenic Technical Services.

\section{CENTRAL RADIO PROPAGATION LABORATORY}

Ionosphere Research and Propagation. Low Frequency and Very Low Frequency Research. Ionosphere Research. Prediction Services. Sun-Earth Relationships. Field Engineering. Radio Warning Services. Vertical Soundings Research.

Radio Propagation Engineering. Data Reduction Instrumentation. Radio Noise. Tropospheric Measurements. Tropospheric Analysis. Propagation-Terrain Effects. Radio-Meteorology. Lower Atmosphere Physics.

Radio Systems. Applied Electromagnetic Theory. High Frequency and Very High Frequency Research. Modula lation Research. Antenna Research. Navigation Systems.

Upper Atmosphere and Space Physics. Upper Atmosphere and Plasma Physics. Ionosphere and Exosphere Scatter. Airglow and Aurora. Ionospheric Radio Astronomy.

\section{RADIO STANDARDS LABORATORY}

Radio Physics. Radio Broadcast Service. Radio and Microwave Materials. Atomic Frequency and Time-Interval Standards. Millimeter-Wave Rese arch.

Circuit Standards. High Frequency Electrical Standards. Microwave Circuit Standards. Electronic Calibration Center. 
NBS .

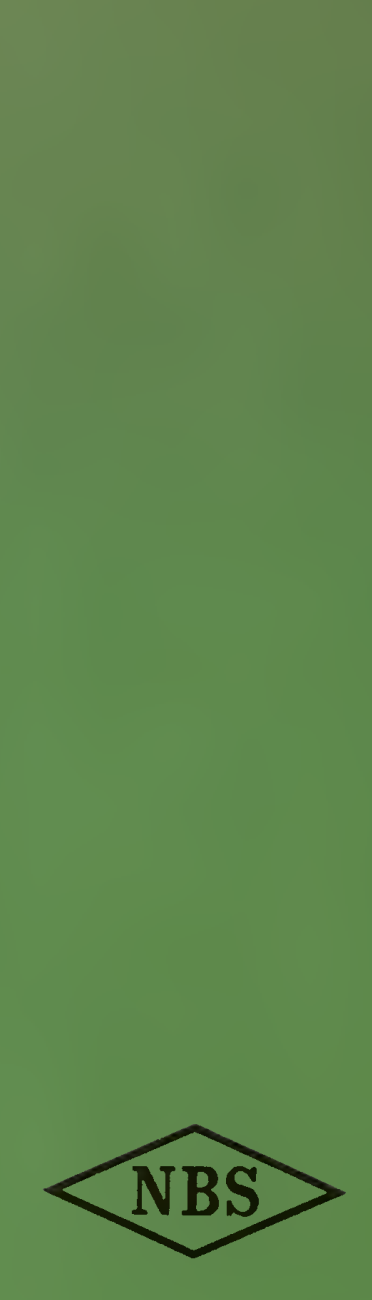

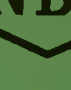

